\title{
Role of Stereotactic Radiotherapy in Cranial Metastases of Small Cell Lung Cancer
}

\author{
(D) Naciye IŞIK, (1) Gökhan YAPRAK, (1) Cengiz GEMici, (1) Özüm ATASOY \\ Department of Radiation Oncology, Kartal Dr. Lütfi Kırdar Training and Research Hospital, İstanbul-Turkey
}

\begin{abstract}
OBJECTIVE
Brain metastasis can be seen in small cell lung cancer patients despite cranial radiotherapy. In case of intracranial recurrence after cranial radiotherapy, treatment choices are restricted. Cranial reirradiation may be an option. In our study, the role of stereotactic radiotherapy after relapse in patients undergoing whole-brain radiotherapy for prophylaxis or metastasis was investigated.
\end{abstract}

\section{METHODS}

Thirty-six small cell lung cancer patients who had intracranial recurrence after total cranial irradiation and who were treated with salvage SRT in our clinic between June 2010 and January 2019 were evaluated retrospectively in this study. The patients were treated using a frameless robotic radiosurgery system (CyberKnife-Accuray, CA, USA). Median 20 Gy (10-24 Gy) was administered in one to four fractions depending on the volume and relation of the tumor with critical structures.

\section{RESULTS}

Whole-brain radiotherapy was performed with cranial prophylaxis in 16 patients (44.5\%) and brain metastasis in 20 patients (55.5\%), in which patients underwent stereotactic radiotherapy (SRT) with recurrence/metastasis. Median follow-up time after SRT was 5.5 months. Median one and two years survival after SRT were $\% 33$ and \%6,6, and median survival was 4,1 months. After SRT, one and twoyear cranial control rates were $57 \%$ and $15 \%$, and the median cranial control duration was 12.8 months. In multivariate analysis, the only time interval between WBRT and SRT was found to be significant for survival after SRT p=0.014 (HR: 2.66 95\% CI:1.21-5.82).

\section{CONCLUSION}

SRT should be considered as a treatment alternative, especially in patients with long time intracranial control after whole-brain radiotherapy and in patients with systemic disease control.

Keywords: Brain metastasis re-irradiation; small cell lung cancer; stereotactic radiotherapy.

Copyright $\odot$ 2020, Turkish Society for Radiation Oncology

\section{Introduction}

Brain metastases are present in $20 \%$ of the patients at initial diagnosis of small cell lung cancer patients and in autopsy series, $80 \%$ of the patients have been detected with brain metastases.[1] New treatment approaches are under evolution for the treatment of brain metastases in small cell lung cancer. Prophylactic cranial irradiation in limited-stage small cell cancer decreases by $25 \%$ the development of cranial metastases and provides survival advantage.[2] After EORTC (European Organization for Research and Treatment of Cancer) 
prospective randomized study, prophylactic cranial irradiation became the standard treatment in extensive-stage small cell lung cancer patients responding to chemotherapy, too.[3] However, another randomized study performed in Japan did not demonstrate survival advantage as observed in the EORTC study when the patients were followed regularly by cranial MRI.[4]

In small cell lung cancer patients with brain metastases, cranial radiotherapy is the standard treatment. Although chemotherapy can cross the blood-brain barrier and provides a certain response in the presence of brain metastases, chemotherapy itself cannot replace radiotherapy.[5] In a phase III EORTC study, Teniposid alone was insufficient to control brain metastases in comparison to Teniposid administered together with cranial irradiation.[6] In patients with isolated cranial metastases, cranial irradiation provided a $50 \%$ response rate and 55\% neurologic control with 5.4 months response duration. However, cranial recurrence is inevitable despite radiotherapy.[7] Today with the integration of immunotherapy to chemotherapy, which provides better systemic control and survival, the probability of cranial recurrence risk may increase.

In case of intracranial recurrence after cranial radiotherapy, treatment choices are restricted. Cranial re-irradiation may be an option and secondary cranial irradiations were reported in the literature for solid tumors.[8] However, due to the detrimental effects of cranial irradiation on cognitive functions, [9-11] cranial re-irradiation may be proposed only to symptomatic patients and for palliative intent. Stereotactic radiotherapy (SRT), on the other hand, maybe less detrimental concerning cognitive functions and can be a better option for cranial re-irradiation.[12,13] However, due to extensive cranial involvement in small cell lung cancer, SRT can be an alternative treatment only in selected cases, and data about the subject are restricted. SRT can be offered to cranial metastases when they are detected with a limited number and volume. These kinds of metastases can be found when the patients are followed regularly with cranial MRI after prophylactic cranial radiotherapy or after treatment of cranial metastatic disease.[14]

In this study, we tried to investigate the role of stereotactic re-irradiation in small cell lung cancer patients who had relapsed after cranial radiotherapy.

\section{Materials and Methods}

Thirty-six small cell lung cancer patients who had intracranial recurrence after total cranial irradiation and who were treated with salvage SRT in our clinic between June 2010 and January 2019 were evaluated retrospectively.

The patients were treated with a frameless robotic radiosurgery system (Cyberknife -Accuracy Incorporated, Sunnyvale, CA, USA). The gross tumor volumes were determined from T1 weighted MRI images with contrast. Planning target volume (PTV) was obtained by adding a 1-2 $\mathrm{mm}$ margin to the gross tumor volume (GTV). Median 20 Gy (10-24 Gy) was administered in 1 to 4 fractions depending on the volume and relation of the tumor with critical structures. Treatment responses were evaluated according to the RECIST criteria.

Overall survival was calculated from the time of primary diagnoses to death or last follow-up, and SRT survival was calculated from the time of SRT treatment to death or last follow-up. The time interval between whole-brain irradiation and stereotactic radiotherapy was calculated from the first day of whole brain radiation therapy (WBRT) and SRT. All the patients were included in the survival analysis. Patients who died within three months after SRT were considered as early deaths even in the absence of radiologic evaluation. These patients were considered as neurologic deaths. Recursive partitioning analysis (RPA), treatment volume, chemotherapy administration after SRT, the interval between WBRT and SRT, systemic disease status at the time of SRT, the reason for initial cranial radiotherapy; prophylactic or treatment of cranial metastases, and initial stage of disease were all evaluated.

Statistical analysis was performed using SPSS version 17.00. A p-value of less than 0.05 was considered significant. Kaplan-Meier method was used for survival analysis and Cox, Log-rank analysis was performed.

\section{Results}

In this study, 29 out of 36 patients were male (80.6\%), and 7 were female (19.4\%). Karnofsky performance status of all the patients was between 80 to 100. Mean age of the patients was 58.9 (min: 30, max: 81). Patients were divided into two groups according to their age, the patients between $30-59$ years (16 patients), and the ones above 60 years of age ( 20 patients). At the time of initial diagnoses, 26 patients $(72.3 \%)$ were staged as limited-stage disease and 10 patients $(27.7 \%)$ as an extensive-stage disease. Whole brain radiotherapy was performed for cranial prophylaxis in 16 patients (44.5\%) and for the treatment of brain metastases in 20 patients $(55.5 \%)$. SRT was administered for intracra- 
nial recurrence after whole brain irradiation with two fractions (range 1-3), and 20 Gy (range 10-24 Gy). While thirteen patients (36\%) were in the RPA1 group, 23 patients (64\%) were in the RPA2 group. SRT was performed for single metastases in 22 patients $(61.2 \%)$, for two to three metastases in 12 patients (33.3\%) and for more than four metastases in two patients (5.5\%). Mean SRT volume was $8 \mathrm{cc}$ (min; 0.5, max; 57.6). Neurologic symptoms like headache, ataxia, and epilepsy were present before SRT in 24 patients. While no cranial recurrence was observed in 11 out of 36 patients (30\%) during the follow-up, 12 patients $(33.3 \%)$ had recurrence outside the SRT volume, and one patient (2.7\%) had a recurrence in the SRT volume. Twelve patients (33.3\%) died within three months after SRT without radiological evaluation.

Median follow-up time after SRT was 5.5 months. Median time interval between WBRT and SRT was 11 months. Median survival was 30.2 months from the time of initial diagnoses. One, two and three years survivals were $91.7 \%, 63.9 \%, 36.1 \%$, respectively. Median one and two years survival after SRT were 33\% and 6.6\%, and median survival was 4,1 months (Fig. 1). Four patients were still alive at the last follow up date (June-2019).

When we look at the prognostic factors like gender, age, disease stage at initial diagnoses, the aim of WBRT, RPA, the number of metastases, volume of metastases, we did not observe any effects of these prognostic factors on survival. While the median survival of patients who were treated with salvage SRT after 11 months from the initial WBRT was 13.5 months, it was only 3.3 months when this interval was below 11 months $(\mathrm{p}<0.05)$. In patients with controlled systemic disease, while the survival was 14.4 months, it was 9.2 months for patients

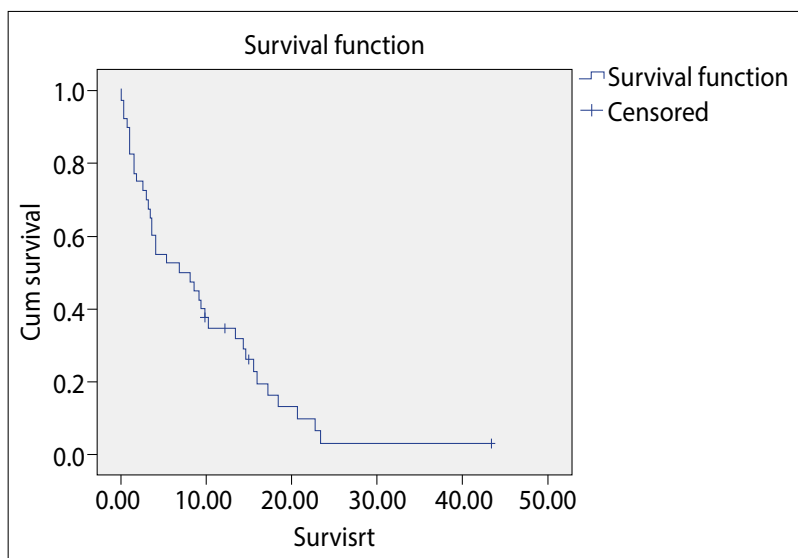

Fig. 1. Post SRT life expectancy. with stable disease, and only 2.9 months in patients with uncontrolled systemic disease $(\mathrm{p}<0.05)$. In multivariate analysis, the only time interval between WBRT and SRT was found to be significant for survival after SRT $\mathrm{p}=0.014$ (HR: 2.66 95\% CI:1.21-5.82) (Table 1).

Two-year local control rate was $86 \%$. One patient was operated for local recurrence 15 months after SRT. This patient is still alive with intracranial control at the last follow-up date. Median cranial control (Infield+outfield disease control) time was 12.8 months. One year cranial control rate was $57 \%$, and a two-year cranial control rate was $15 \%$.

When the factors that had an effect on cranial control (Table 2), one- and two-years neurologic progression-free survivals were $47.3 \%$ and $12.6 \%$, respectively. Median neurologic progression-free survival was 10.3 months.

\begin{tabular}{|c|c|c|}
\hline & \multicolumn{2}{|c|}{ Post SRT life expectancy } \\
\hline & Time (month) & $\mathbf{p}$ \\
\hline \multicolumn{3}{|l|}{ Gender } \\
\hline Woman & 9.2 & 0.95 \\
\hline Man & 4 & \\
\hline \multicolumn{3}{|l|}{ Age } \\
\hline 18-59 & 9.2 & 0.11 \\
\hline$\geq 60$ & 3.2 & \\
\hline \multicolumn{3}{|c|}{ Stage of the diagnosis } \\
\hline Limit & 4.1 & 0.76 \\
\hline Extensive & 3.5 & \\
\hline \multicolumn{3}{|l|}{ WBRT reason } \\
\hline Metastasis & 4 & 0.86 \\
\hline Prophylactic & 4.1 & \\
\hline \multicolumn{3}{|l|}{ RPA } \\
\hline 1 & 10.4 & 0.18 \\
\hline 2 & 4 & \\
\hline \multicolumn{3}{|c|}{ Number of metastases in SRT } \\
\hline 1 & 3.5 & 0.93 \\
\hline $2-5$ & 4.1 & \\
\hline \multicolumn{3}{|l|}{ SRT volume } \\
\hline$<8 \mathrm{cc}$ & 2.9 & 0.09 \\
\hline$\geq 8 \mathrm{cc}$ & 13.5 & \\
\hline \multicolumn{3}{|c|}{ WBRT-SRT interval } \\
\hline 11 month $\leq$ & 13.5 & 0.001 \\
\hline 11 month> & 3.3 & \\
\hline \multicolumn{3}{|c|}{ Systemic disease during SRT } \\
\hline Remission & 14.4 & 0.01 \\
\hline Stable & 9.2 & \\
\hline Progression & 2.9 & \\
\hline
\end{tabular}

WBRT: Whole brain radiation therapy; SRT: Stereotactic radiotherapy 


\begin{tabular}{|c|c|c|}
\hline & \multicolumn{2}{|c|}{ Post SRT cranial control } \\
\hline & Time (month) & $\mathbf{p}$ \\
\hline \multicolumn{3}{|l|}{ Gender } \\
\hline Woman & 6.2 & 0.81 \\
\hline Man & 12.8 & \\
\hline \multicolumn{3}{|l|}{ Age } \\
\hline 18-59 & 12.8 & 0.3 \\
\hline$>60$ & 13.8 & \\
\hline \multicolumn{3}{|c|}{ Stage of diagnosis } \\
\hline Limited & 16.8 & 0.05 \\
\hline Extensive & 10.5 & \\
\hline \multicolumn{3}{|l|}{ WBRT reason } \\
\hline Metastasis & 12.8 & 0.28 \\
\hline Prophylactic & - & \\
\hline \multicolumn{3}{|l|}{ RPA } \\
\hline 1 & 12.8 & 0.36 \\
\hline 2 & 3.3 & \\
\hline \multicolumn{3}{|c|}{ Number of the metastases in SRT } \\
\hline 1 & 13.8 & 0.19 \\
\hline $2-5$ & 10.5 & \\
\hline \multicolumn{3}{|l|}{ SRT volume } \\
\hline$<8 c c$ & 16.8 & 0.67 \\
\hline$>8 \mathrm{cc}$ & 13.8 & \\
\hline \multicolumn{3}{|c|}{ WBRT-SRT interval } \\
\hline 11 month $\leq$ & 12.8 & 0.64 \\
\hline 11 month> & 13.8 & \\
\hline \multicolumn{3}{|c|}{ Systemic disease during SRT } \\
\hline Remission & 13.8 & 0.99 \\
\hline Stable & 12.8 & \\
\hline Progression & - & \\
\hline
\end{tabular}

WBRT: Whole brain radiation therapy; SRT: Stereotactic radiotherapy

When 13 patients who died within three months after SRT were evaluated, we realized that these patients had a shorter interval between WBRT and SRT, and they had neurologic symptoms more than the others (Chi-square $\mathrm{p}=0.05$ ).

\section{Discussion}

Cranial involvement is one of the most important causes of death in small cell lung cancer patients. [15] In extensive-stage disease, an EORTC phase II study demonstrated that brain control was the most important prognostic factor for survival.[6] After several randomized studies, comparing whole brain radiotherapy with stereotactic radiotherapy in the treatment of cranial metastases of solid tumors rather than small cell lung cancer, stereotactic cranial radio- therapy became the standard treatment due to better quality of life, and better preservation of cognitive functions.[9] However, whole brain irradiation is still the standard treatment in small cell lung cancer due to extensive intracranial involvement. There are studies investigating the role of SRT in small cell lung cancer.[16] Robin et al. reported better survival (10.8 months versus 7.1 months) with SRT in their observational study comprising 5752 whole brain irradiation and 200 stereotactic irradiation.[17] Multivariate analysis with SRT, including comorbidity, age, gender, ethnicity, disease stage and SRT, demonstrated survival advantage with SRT. Studies are needed to better investigate the role of SRT in the treatment of cranial metastases from small cell lung cancer.

Local treatments in solid tumor cranial metastases play an important role. Inclusion of whole brain radiotherapy after surgical resection of cranial metastases or the addition of SRS (stereotactic radiosurgery) to whole brain radiotherapy in single brain metastases provides survival advantage.[18,19] Whole brain radiotherapy is the preferred treatment in small-cell lung cancer due to the disseminated involvement of brain. [20] On the other hand, Bernhardt, in a retrospective analysis, demonstrated better prognosis with surgery in treatment of single brain metastases of small cell lung cancer.[21] Local approaches have not been tested sufficiently in the treatment of small cell lung cancer patients. There is not much treatment alternative after cranial recurrence in patients who underwent whole brain radiotherapy either for cranial prophylaxis or for cranial metastases. SRS may be investigated in these patients, especially with a limited number of metastases.

Cranial recurrence is inevitable despite cranial radiotherapy and carries a worse prognosis in small cell lung cancer. In our study, median overall survival after SRT was not sufficient and only found as 4.1 months. Several retrospective series demonstrated survivals ranging from 4.5 months to 16.9 months with salvage SRT in small cell lung cancer patients after cranial relapse.[22-24] In the study reported by Harris, they found $57 \%$ local control rate, and they expressed the insufficiency of SRT with a dose of $18 \mathrm{~Gy}$ in local control of the cranial metastases.[24] In addition to radiation, dose is important in local control, they also found that chemotherapy administration played an important role in cranial disease control. In a series where SRT dose was above $20 \mathrm{~Gy}$, the local control rates were found between $85-90 \%$.[22-24] In our study, only one patient had local recurrence with $85 \%$ local control rate. 
Harris et al., in their study, reported cranial recurrence rate as $58 \%$ in 1 -year and $75 \%$ in two years after salvage SRT.[24] Distant brain failure was observed within three months. The most important factor for distant brain recurrence was the presence of multiple cranial metastases.[24] Nakazaki et al. reported a 50\% recurrence risk within six months, especially with a higher incidence in patients with multiple brain metastases and meningeal involvement.[23] In our study, the median brain control time was 12.8 months with a control rate of $57 \%$ in one year.

Recursive partitioning analysis (RPA) [25] and graded prognostic assessment (GPA) were the two validated scoring systems to investigate the survival in patients with brain metastases.[26] While RPA considers the age, extracranial disease and performance status of the patients, GPA considers the histologic diagnosis, as well. In recurrent cranial metastases while these scoring systems can be utilized, new scoring system proposals are also present.[27] In recurrent metastases and re-irradiated patients, low-performance scores, the presence of extracranial disease and small cell histology were associated with poor prognosis.[27] We did not find RPA as a prognostic factor in our patients.

Yamamoto et al. have shown that SRT has the same efficacy even in patients with more than four intracranial metastases in solid tumors.[28] Other than tumor volume, the number of intracranial metastases does not preclude treatment with SRT. There are retrospective studies demonstrating no detrimental effect of the number of intracranial metastases treated with SRT in patients with small-cell lung cancer.[22,29] Nakazaki et al. reported the prognostic significance of the number of intracranial metastases.[23] While in series where no difference was observed concerning the number of metastases, SRT was performed only for one to four metastases. Nakazaki et al. treated more than four cranial metastases with SRT besides one to three metastases, too. In their study, 39\% of the patients received SRT for more than 10 metastases (median 5). The prognosis was worse for patients with more than 10 metastases in this study.[23] A significant number of patients in our study received SRT for one to four metastases and no correlation was observed between the number of metastases and survival.

Age, small target volume, the interval between WBRT and salvage SRT, systemic control of the primary disease, KPS, number of metastases, and histology were found to be prognostic in patients treated with salvage SRT arising from different primary tu- mors, including small cell lung cancer.[30] Nakazaki et al. found that the number of metastases, meningeal involvement, tumor size, and KPS as prognostic factors for patients undergoing salvage SRT.[23] Sheehan, on the other hand, found KPS, tumor volume, the interval between initial diagnoses and cranial recurrence as prognostic for salvage SRS.[22]

Hariss et al. defined systemic disease control and concomitant chemotherapy as prognostic for salvage SRT.[24] We found the time interval between WBRT and salvage SRT as a prognostic factor for our patients. Bernhardt et al. found chemotherapy resistance as the most important prognostic factor in multivariate analysis in small cell lung cancer patients with single brain metastases.[21] Systemic disease control outside the brain has an effect on the results. We think that intracranial disease control becomes important in small cell lung cancer if systemic disease can be controlled.

Brain tissue is different from other tissues by its different microenvironment and its special immune system and blood brain barrier. Although chemotherapy provides a response, no survival benefit was seen with chemotherapy.[31] In phase III randomized RTOG study in non-small cell lung cancer, brain metastases, the addition of erlotinib or temozolomide to the radiotherapy increased the toxicity and decreased survival. [32] The role of targeted treatments and immunotherapies are being investigated actively in NSCLC brain metastases. There are few data demonstrating the efficacy of chemotherapy in small cell lung cancer patients with brain metastases. Harris et al. reported better survival when chemotherapy continued after salvage SRT. [24] The better result with chemotherapy may be due to the extracranial disease control.[22,24] In our study, patients with extracranial disease control had better survival as well. Systemic disease control determines the prognosis after salvage SRT. In patients under systemic disease control or patients who have effective treatment for the systemic disease may have better results after salvage SRT.

\section{Conclusion}

The most important limitation of our study is that this study was performed retrospectively with a small number of patients. At the same time, the radiologic response could not be evaluated in all patients due to early deaths. SRT should be considered as a treatment alternative, especially in patients with long time intracranial control after whole brain radiotherapy and in patients with systemic disease control. 
Peer-review: Externally peer-reviewed.

Conflict of Interest: None declared.

Ethics Committee Approval: This is a retrospective study.

Financial Support: None declared.

Authorship contributions: Concept - N.I., G.Y.; Design G.Y., C.G.; Supervision - C.G., Ö.A.; Funding - None; Materials - N.I., Ö.A.; Data collection and/or processing - Ö.A.; Data analysis and/or interpretation - N.I.; Literature search - G.Y.; Writing - C.G.; Critical review - N.I., G.Y.

\section{References}

1. Nugent JL, Bunn PA Jr, Matthews MJ, Ihde DC, Cohen $\mathrm{MH}$, Gazdar A, et al. CNS metastases in small cell bronchogenic carcinoma: increasing frequency and changing pattern with lengthening survival. Cancer 1979;44(5):1885-93.

2. Aupérin A, Arriagada R, Pignon JP, Le Péchoux C, Gregor A, Stephens RJ, et al. Prophylactic Cranial Irradiation Overview Collaborative Group, Prophylactic cranial irradiation for patients with small-cell lung cancer in complete remission. $\mathrm{N}$ Engl J Med 1999;341(7):476-84.

3. Slotman B, Faivre-Finn C, Kramer G, Rankin E, Snee M, Hatton M, et al. Prophylactic cranial irradiation in extensive small-cell lung cancer. $\mathrm{N}$ Engl J Med 2007;357(7):664-72.

4. Takahashi T, Yamanaka T, Seto T, Harada H, Nokihara $\mathrm{H}$, Saka H, et al. Prophylactic cranial irradiation versus observation in patients with extensive-disease smallcell lung cancer: a multicentre, randomised, open-label, phase 3 trial. Lancet Oncol 2017;18(5):663-71.

5. Lukas RV, Gondi V, Kamson DO, Kumthekar P, Salgia R. State-of-the-art considerations in small cell lung cancer brain metastases. Oncotarget 2017;8(41):71223-33.

6. Postmus PE, Haaxma-Reiche H, Smit EF, Groen HJ, Karnicka H, Lewinski $\mathrm{T}$, et al.Treatment of brain metastases of small-cell lung cancer: comparing teniposide and teniposide with whole-brain radiotherapy-a phase III study of the European Organization for the Research and Treatment of Cancer Lung Cancer Cooperative Group. J Clin Oncol 2000;18(19):3400-8.

7. Postmus PE, Haaxma-Reiche H, Gregor A, Groen HJ, Lewinski T, Scolard T, et al. Brain-only metastases of small cell lung cancer; efficacy of whole brain radiotherapy. Radiother Oncol 1998;46(1):29-32.

8. Ozgen Z, Atasoy BM, Kefeli AU, Seker A, Dane F, Abacioglu $U$. The benefit of whole brain reirradiation in patients with multiple brain metastases. Radiat Oncol 2013;8:186.

9. Chang EL, Wefel JS, Hess KR, Allen PK, Lang FF, Kornguth DG, et al. Neurocognition in patients with brain metastases treated with radiosurgery or radiosurgery plus whole-brain irradiation: a randomised controlled trial. Lancet Oncol 2009;10(11):1037-44.

10. Wolfson AH, Bae K, Komaki R, Meyers C, Movsas B, Le Pechoux C, et al. Primary analysis of a phase II randomized trial Radiation Therapy Oncology Group (RTOG) 0212: Impact of different total doses and schedules of prophylactic cranial irradiation on chronic neurotoxicity and quality of life for patients with limited-disease small-cell lung cancer. Int J Radiat Oncol Biol Phys 2011;81(1):77-84.

11. Gondi V, Paulus R, Bruner DW, Meyers CA, Gore EM, Wolfson A, A et al. Decline in tested and self-reported cognitive functioning after prophylactic cranial irradiation for lung cancer: Pooled secondary analysis of radiation therapy oncology group randomized trials 0212 and 0214. Int J Radiat Oncol Biol Phys 2013;86(4):656-64.

12. Chao ST, Barnett GH, Vogelbaum MA, Angelov L, Weil RJ, Neyman G, et al. Salvage stereotactic radiosurgery effectively treats recurrences from whole-brain radiation therapy. Cancer. 2008;113(8):2198-204.

13. Isık N, Kocak Erdoğan M, Mayadağlı A, Gemici C, SG Karabulut, Gedik D. Re-Irradiation of Progressive Brain Metastases After Whole Brain Radiotherapy: Outcome of Stereotactic Radiosurgery. Journal of Neurological Sciences 2012;29(1):82-91.

14. Kushnirsky M, Nguyen V, Katz JS, Steinklein J, Rosen L, Warshall C, et al. Time-delayed contrast-enhanced MRI improves detection of brain metastases and apparent treatment volumes. J Neurosurg 2016;124(2):489-95.

15. Lagerwaard FJ, Levendag PC, Nowak PJ, Eijkenboom WM, Hanssens PE, Schmitz PI. Identification of prognostic factors in patients with brain metastases: A review of 1292 patients. Int J Radiat Oncol Biol Phys 1999;43(4):795-803.

16. Jiang W, Haque W, Verma V, Butler B, Teh BS. Stereotactic radiosurgery for brain metastases from newly diagnosed small cell lung cancer: practice patterns and outcomes. Acta Oncol 2019;58(4):491-8.

17. Robin TP, Jones BL, Amini A, Koshy M, Gaspar LE, Liu AK, et al. Radiosurgery alone is associated with favorable outcomes for brain metastases from small-cell lung cancer. Lung Cancer 2018;120:88-90.

18. Patchell RA, Tibbs PA, Walsh JW, Dempsey RJ, Maruyama Y, Kryscio RJ, et al. A randomized trial of surgery in the treatment of single metastases to the brain. N Engl J Med 1990;322(8):494-500.

19. Andrews DW, Scott CB, Sperduto PW, Flanders AE, Gaspar LE, Schell MC, et al. Whole brain radiation therapy with or without stereotactic radiosurgery boost for patients with one to three brain metastases: phase III results of the RTOG 9508 randomised trial. Lancet 2004;363(9422):1665-72. 
20. Kalemkerian GP, Akerley W, Bogner P, Borghaei H, Chow LQ, Downey RJ, et al. Small cell lung cancer. J Natl Compr Canc Netw 2013;11:78-98.

21. Bernhardt D, Adeberg S, Bozorgmehr F, Opfermann N, Hörner-Rieber J, König L, et al. Outcome and prognostic factors in single brain metastases from small-cell lung cancer. Strahlenther Onkol 2018;194(2):98-106.

22. Sheehan J, Kondziolka D, Flickinger J, Lunsford LD. Radiosurgery for patients with recurrent small cell lung carcinoma metastatic to the brain: outcomes and prognostic factors. J Neurosurg 2005;102:247-54.

23. Nakazaki K, Higuchi Y, Nagano O, Serizawa T. Efficacy and limitations of salvage gamma knife radiosurgery for brain metastases of small-cell lung cancer after whole-brain radiotherapy. Acta Neurochir (Wien) 2013;155(1):107-14.

24. Harris S, Chan MD, Lovato JF, Ellis TL, Tatter SB, Bourland JD, Munley MT, deGuzman AF, Shaw EG, Urbanic JJ, McMullen KP. Gamma knife stereotactic radiosurgery as salvage therapy after failure of wholebrain radiotherapy in patients with small-cell lung cancer. Int J Radiat Oncol Biol Phys 2012;83(1):e53-9.

25. Gaspar LE, Scott C, Murray K, Curran W. Validation of the RTOG recursive partitioning analysis (RPA) classification for brain metastases. Int J Radiat Oncol Biol Phys 2000;47(4):1001-6.

26. Sperduto PW, Chao ST, Sneed PK, Luo X, Suh J, Roberge D, et al. Diagnosis-specific prognostic factors, indexes, and treatment outcomes for patients with newly diagnosed brain metastases: a multi-institutional analysis of 4,259 patients. Int J Radiat Oncol Biol Phys 2010;77(3):655-61.
27. Logie N, Jimenez RB, Pulenzas N, Linden K, Ciafone $\mathrm{D}$, Ghosh S, et al. Estimating prognosis at the time of repeat whole brain radiation therapy for multiple brain metastases: The reirradiation score. Adv Radiat Oncol 2017;2(3):381-90.

28. Yamamoto M, Serizawa T, Shuto T, Akabane A, Higuchi Y, Kawagishi J, et al. Stereotactic radiosurgery for patients with multiple brain metastases (JLGK0901): a multi-institutional prospective observational study. Lancet Oncol 2014;15(4):387-95.

29. Wegner RE, Olson AC, Kondziolka D, Niranjan A, Lundsford LD, Flickinger JC. Stereotactic radiosurgery for patients with brain metastases from small cell lung cancer. Int J Radiat Oncol Biol Phys 2011;81(3):e21-e7.

30. Caballero JA, Sneed PK, Lamborn KR, Ma L, Denduluri S, Nakamura JL, Barani IJ, McDermott MW. Prognostic factors for survival in patients treated with stereotactic radiosurgery for recurrent brain metastases after prior whole brain radiotherapy. Int J Radiat Oncol Biol Phys 2012;83(1):303-9.

31. Arvold ND, Lee EQ, Mehta MP, Margolin K, Alexander BM, Lin NU, et al. Updates in the management of brain metastases. Neuro Oncol 2016;18(8):1043-65.

32. Sperduto PW, Wang M, Robins HI, Schell MC, Werner-Wasik M, Komaki R, et al. A phase 3 trial of whole brain radiation therapy and stereotactic radiosurgery alone versus WBRT and SRS with temozolomide or erlotinib for non-small cell lung cancer and 1 to 3 brain metastases: Radiation Therapy Oncology Group 0320. Int J Radiat Oncol Biol Phys 2013;85(5):1312-8. 